\title{
A Modified TOPSIS Method Based on $D$ Numbers and Its Applications in Human Resources Selection
}

\author{
Liguo Fei, ${ }^{1}$ Yong Hu, ${ }^{2}$ Fuyuan Xiao, ${ }^{1}$ Luyuan Chen, ${ }^{1}$ and Yong Deng ${ }^{1,2,3,4}$ \\ ${ }^{1}$ School of Computer and Information Science, Southwest University, Chongqing 400715, China \\ ${ }^{2}$ Big Data Decision Institute, Jinan University, Tianhe, Guangzhou 510632, China \\ ${ }^{3}$ Institute of Integrated Automation, School of Electronic and Information Engineering, Xian Jiaotong University, Xian, Shaanxi \\ 710049, China \\ ${ }^{4}$ School of Engineering, Vanderbilt University, Nashville, TN 37235, USA
}

Correspondence should be addressed to Yong Deng; prof.deng@hotmail.com

Received 29 February 2016; Accepted 28 April 2016

Academic Editor: Rita Gamberini

Copyright (c) 2016 Liguo Fei et al. This is an open access article distributed under the Creative Commons Attribution License, which permits unrestricted use, distribution, and reproduction in any medium, provided the original work is properly cited.

\begin{abstract}
Multicriteria decision-making $(\mathrm{MCDM})$ is an important branch of operations research which composes multiple-criteria to make decision. TOPSIS is an effective method in handling MCDM problem, while there still exist some shortcomings about it. Upon facing the MCDM problem, various types of uncertainty are inevitable such as incompleteness, fuzziness, and imprecision result from the powerlessness of human beings subjective judgment. However, the TOPSIS method cannot adequately deal with these types of uncertainties. In this paper, a D-TOPSIS method is proposed for MCDM problem based on a new effective and feasible representation of uncertain information, called $D$ numbers. The $D$-TOPSIS method is an extension of the classical TOPSIS method. Within the proposed method, $D$ numbers theory denotes the decision matrix given by experts considering the interrelation of multicriteria. An application about human resources selection, which essentially is a multicriteria decision-making problem, is conducted to demonstrate the effectiveness of the proposed $D$-TOPSIS method.
\end{abstract}

\section{Introduction}

Multicriteria decision-making (MCDM) or multiple-criteria decision analysis is an important branch of operations research that definitely uses multiple-criteria in decisionmaking environments $[1,2]$. In daily life and professional learning, there exist generally multiple conflicting criteria which need to be considered in making decisions and optimization $[3,4]$. Price and spend are typically one of the main criteria with regard to a large amount of practical problems. However, the factor of quality is generally another criterion which is in conflict with the price. For example, the cost, safety, fuel economy, and comfort should be considered as the main criteria upon purchasing a car. It is the most benefit for us to select the safest and most comfortable one which has the bedrock price simultaneously. The best situation is obtaining the highest returns while reducing the risks to the most extent with regard to portfolio management. In addition, the stocks that have the potential of bringing high returns typically also carry high risks of losing money. In service industry, there is a couple of conflicts between customer satisfaction and the cost to provide service. Upon making decision, it will be compelling if multiple-criteria are considered even though they came from and are based on subjective judgment of human. What is more, it is significant to reasonably describe the problem and precisely evaluate the results based on multiple-criteria when the stakes are high. With regard to the problem of whether to build a chemical plant or not and where the best site for it is, there exist multiple-criteria that need to be considered; also, there are multiple parties that will be affected deeply by the consequences.

Constructing complex problems properly as well as multiple-criteria taken into account explicitly results in more reasonable and better decisions. Significant achievements in this field have been made since the beginning of the modern multicriteria decision-making (MCDM) discipline 
in the early 1960s. A variety of approaches and methods have been proposed for MCDM. In [5], a novel MCDM method named FlowSort-GDSS is proposed to sort the failure modes into priority classes by involving multiple decision-makers, which has the robust advantages in sorting failures. In the field of multiple objective mathematical programming, Evans and $\mathrm{Yu}[6,7]$ proposed the vector maximization method aimed at approximating the nondominated set which is originally developed for multiple objective linear programming problems. Torrance [8] used elaborate interview techniques to deal with the problem in MCDM, which exist for eliciting linear additive utility functions and multiplicative nonlinear utility functions. And there are many other methods, such as best worst method [9], characteristic objects method [10], fuzzy sets method [11-13], rough sets [14], and analytic hierarchy process [15-17]. In [18], the authors aim to systematically review the applications and methodologies of the MCDM techniques and approaches, which is a good guidance for us to fully understand the MCDM. Technique for order preference by similarity to ideal solution (TOPSIS), which is proposed in [19-23], is a ranking method in conception and application. The standard TOPSIS methodology aims to select the alternatives which have the shortest distance from the positive ideal solution and the longest distance from the negative ideal solution at the same time. The positive ideal solution maximizes the benefit attributes and minimizes the cost attributes, whereas the negative ideal solution maximizes the cost attributes and minimizes the benefit attributes. The TOPSIS methodology is applied widely in MCDM field [2427], especially in the fuzzy extension of linguistic variables [28-31].

It is obvious that the mentioned approaches play a role under some specific circumstances, but, in the practical applications, they show more uncertainties due to the subjective judgment of experts' assessment. In order to effectively handle various uncertainties involved in the MCDM problem, a new representation of uncertain information, called $D$ numbers [32], is presented in this paper. It is an extension of Dempster-Shafer evidence theory. It gives the framework of nonexclusive hypotheses, applied to many decision-making problems under uncertain environment [33-38]. Comparing with existing methods, $D$ numbers theory can efficiently denote uncertain information and more coincide with the actual conditions.

Therefore, in this paper, to well address these issues in TOPSIS method, an extended version is presented based on $D$ numbers named $D$-TOPSIS, which considers the interrelation of multicriteria and handles the fuzzy and uncertain criteria effectively. The $D$-TOPSIS method can represent uncertain information more effectively than other group decision support systems based on classical TOPSIS method, which cannot adequately handle these types of uncertainties. An application has been conducted using the D-TOPSIS method in human resources selection, and the result can be more reasonable because of its consideration about the interrelation of multiple-criteria.

The remainder of this paper is constituted as follows. Section 2 introduces the Dempster-Shafer theory and its basic rules and some necessary related concepts about $D$ numbers theory and its distance function and TOPSIS. The proposed $D$-TOPSIS method is presented in Section 3. Section 4 conducts an application in human resources selection based on $D$-TOPSIS. Conclusion is given in Section 5.

\section{Preliminaries}

2.1. Dempster-Shafer Evidence Theory. Dempster-Shafer evidence theory $[39,40]$, which is first developed by Dempster and later extended by Shafer, is used to manage various types of uncertain information [41-44], belonging to the category of artificial intelligence. As a theory widely applied under the uncertain environment, it needs weaker conditions and has a wider range of use than the Bayesian probability theory. When the ignorance is confirmed, Dempster-Shafer theory could convert into Bayesian theory, so it is often regarded as an extension of the Bayesian theory. Dempster-Shafer theory has the advantage to directly express the "uncertainty" by assigning the probability to the subsets of the union set composed of multiple elements, rather than to each of the single elements. Besides, it has the ability to combine pairs of bodies of evidence or belief functions to generate a new evidence or belief function $[45,46]$.

The decision-making or optimization in real system is very complex with incomplete information [47-49]. With the superiority in dealing with uncertain information and the practicability in engineering, a number of applications of D-S evidence theory have been published in the literature indicating its widespread for fault diagnosis [50, 51], pattern recognition [52-54], supplier selection [55, 56], and risk assessment $[57,58]$. Also, it exerts a great effect on combining with other theories and methods such as fuzzy numbers [59], decision-making [60], and AHP [61-63]. Moreover, based on the Dempster-Shafer theory, the generalized evidence theory has been proposed by Deng to develop the classical evidence theory [64] to handle conflicting evidence combination [65]. It should be noted that the combination of dependent evidence is still an open issue $[66,67]$. For a more detailed explanation of evidence theory, some basic concepts are introduced as follows.

Definition 1 (frame of discernment). A frame of discernment is a set of alternatives perceived as distinct answers to a question. Suppose $U$ is the frame of discernment of researching problem, a finite nonempty set of $N$ elements that are mutually exclusive and exhaustive, indicated by

$$
U=\left\{E_{1}, E_{2}, \ldots, E_{i}, \ldots, E_{n}\right\}
$$

and denote $2^{U}$ as the power set composed of $2^{N}$ elements of $U$, and each element of $2^{U}$ is regarded as a proposition. Based on the two conceptions, mass function is defined as below.

Definition 2 (mass function). For a frame of discernment $U$, a mass function is a mapping $m$ from $2^{U}$ to $[0,1]$, formally defined by

$$
m: 2^{U} \longrightarrow[0,1]
$$




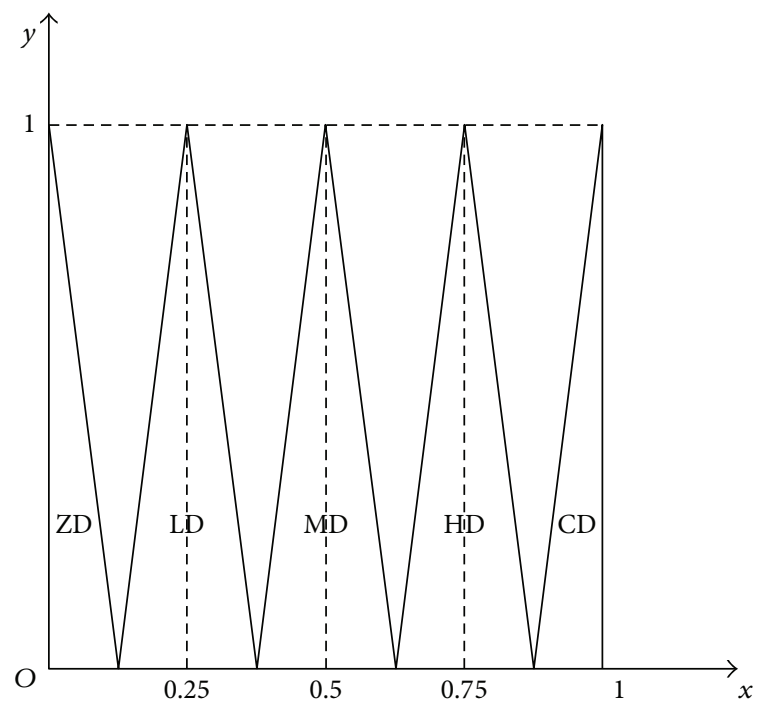

(a) Dempster-Shafer evidence theory

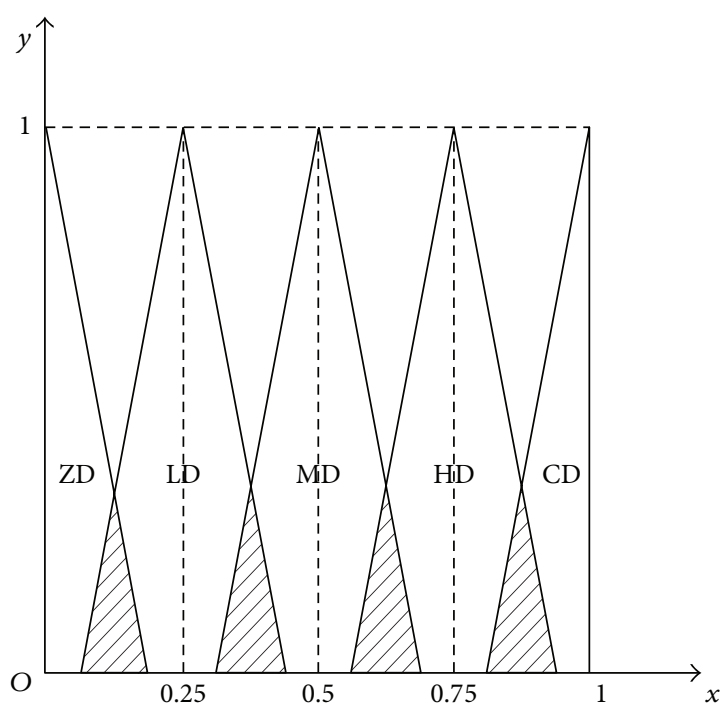

(b) $D$ number theory

FIGURE 1: The framework of DSET and DNT.

satisfying

$$
\begin{aligned}
m(\emptyset) & =0, \\
\sum_{A \in 2^{U}} m(A) & =1,
\end{aligned}
$$

where $\emptyset$ is an empty set and $A$ represents the propositions.

In Dempster-Shafer theory, $m$ is also named as basic probability assignment (BPA), and $m(A)$ is named as assigned probability, presenting how strong the evidence supports $A$. $A$ is regarded as a focal element when $m(A)>0$, and the union of all focal elements are called the core of the mass function.

Considering two pieces of evidence from different and independent information sources, denoted by two BPAs $m_{1}$ and $m_{2}$, Dempster's rule of combination is used to derive a new BPA from two BPAs.

Definition 3 (Dempster's rule of combination). Dempster's rule of combination, also known as orthogonal sum, is expressed by $m=m_{1} \oplus m_{2}$, defined as follows:

$$
m(A)= \begin{cases}\frac{1}{1-K} \sum_{A_{1} \cap A_{2}=A} m_{1}\left(A_{1}\right) m_{2}\left(A_{2}\right), & A \neq \emptyset ; \\ 0, & A=\emptyset\end{cases}
$$

with

$$
K=\sum_{A_{1} \cap A_{2}=\emptyset} m_{1}\left(A_{1}\right) m_{2}\left(A_{2}\right),
$$

where $K$ is a normalization constant, called conflict coefficient of two BPAs. Note that the Dempster-Shafer evidence theory is only applicable to such two BPAs which satisfy the condition $K<1$.
2.2. D Number Theory. D number theory, proposed by Deng [32], is a generalization of Dempster-Shafer evidence theory. A wide range of applications have been published based on it, especially in the uncertain environment and MCDM [33]. In the classical Dempster-Shafer theory, there are several strong hypotheses on the frame of discernment and basic probability assignment. However, some shortcomings still exist which limit the representation of some types of information as well as the restriction of the application in practice. $D$ number theory, considered as an extension and developed method, makes the following progress.

First, Dempster-Shafer evidence theory deals with the problem about the strong hypotheses, which means that elements in the frame of discernment are required to be mutually exclusive. In general, the frame of discernment is determined by experts, always involving human being's subjective judgments and uncertainty. Hence, the hypothesis is hard to meet. For example, there are five anchor points "zero dependence [ZD]," "low dependence [LD]," "moderate dependence $[\mathrm{MD}]$," "high dependence [HD]," and "complete dependence [CD]" corresponding to dependence levels available to analysts to make judgments. It is inevitable that there exist some overlaps of human being's subjective judgments. $D$ number theory is more suitable to the actual situation based on the framework of nonexclusive hypotheses. The difference between Dempster-Shafer theory and $D$ number theory about this is shown in Figure 1.

Second, the problem solved by $D$ number theory without another hypothesis of Dempster-Shafer theory is related to basic probability assignment. In Dempster-Shafer theory, the sum of BPAs must be equal to 1 , which means that the experts have to make all the judgments and then give the assessment results. Nevertheless, on the one hand, it would be difficult to satisfy in some complex environment. On the other hand, from time to time, it would be unnecessary and redundant to 
meet the hypothesis, when the framework does not contain overall situations. From this point of view, $D$ number theory allows the incompleteness of information, having the ability to adapt to more cases.

Third, compared with Dempster-Shafer theory, $D$ number theory is more suitable to the framework. In DempsterShafer theory, the BPA is calculated through the power set of the frame of discernment. It is hard to work when there are too many elements in it, and it even can not be accepted when the number of the frameworks is too high to use Dempster's rule of combination to some degree. $D$ number theory emphasizes the set of problem domains itself. Uncertain information is represented by $D$ numbers so that the fusion would have less calculation and allows arbitrary framework.

Even so, $D$ numbers theory is still preferable in many cases, for the advantages of all the three points above, not just improving one certain aspect. It is defined as follows.

Definition 4 ( $D$ number). Let a finite nonempty set $\Omega$ denote the problem domain. $D$ number function is a mapping formulated by

$$
D: \Omega \longrightarrow[0,1]
$$

with

$$
\begin{aligned}
D(\emptyset) & =0, \\
\sum_{B \subseteq \Omega} D(B) & \leqslant 1
\end{aligned}
$$

and, compared with the mass function, the structure of the expression seems to be similar. However, in $D$ number theory, the elements of $\Omega$ do not require to be mutually exclusive. In addition, being contrary to the frame of discernment $U$ containing overall events, $\Omega$ is suitable to incomplete information by $\sum_{B \subseteq \Omega} D(B)<1$.
Furthermore, for a discrete set $\Omega=\left\{b_{1}, b_{2}, \ldots, b_{i}, \ldots, b_{n}\right\}$, where $b_{i} \in R$, and when $i \neq j, b_{i} \neq b_{j}$. A special form of $D$ numbers can be expressed by

$$
\begin{gathered}
D\left(\left\{b_{1}\right\}\right)=v_{1} \\
D\left(\left\{b_{2}\right\}\right)=v_{2} \\
\vdots \\
D\left(\left\{b_{i}\right\}\right)=v_{i} \\
\vdots \\
D\left(\left\{b_{n}\right\}\right)=v_{n}
\end{gathered}
$$

or simply denoted as $D=\left\{\left(b_{1}, v_{1}\right),\left(b_{2}, v_{2}\right), \ldots,\left(b_{i}, v_{i}\right), \ldots\right.$, $\left.\left(b_{n}, v_{n}\right)\right\}$, where $v_{i}>0$ and $\sum_{i=1}^{n} v_{i} \leq 1$.

Below is the combination rule, a kind of addition operation to combine two $D$ numbers.

Definition 5 (two $D$ numbers' rule of combination). Suppose $D_{1}$ and $D_{2}$ are two $D$ numbers, indicated by

$$
\begin{aligned}
& D_{1}=\left\{\left(b_{1}^{1}, v_{1}^{1}\right), \ldots,\left(b_{i}^{1}, v_{i}^{1}\right), \ldots,\left(b_{n}^{1}, v_{n}^{1}\right)\right\}, \\
& D_{2}=\left\{\left(b_{1}^{2}, v_{1}^{2}\right), \ldots,\left(b_{j}^{2}, v_{j}^{2}\right), \ldots,\left(b_{m}^{2}, v_{m}^{2}\right)\right\},
\end{aligned}
$$

and the combination of $D_{1}$ and $D_{2}$, which is expressed as $D=$ $D_{1} \oplus D_{2}$, is defined as follows:

$$
D(b)=v
$$

with

$$
\begin{aligned}
& b=\frac{b_{i}^{1}+b_{j}^{2}}{2}, \\
& v=\frac{\left(v_{i}^{1}+v_{j}^{2}\right) / 2}{C}, \\
& C=\left\{\begin{array}{ll}
\sum_{j=1}^{m} \sum_{i=1}^{n}\left(\frac{v_{i}^{1}+v_{j}^{2}}{2}\right), & \sum_{i=1}^{n} v_{i}^{1}=1, \sum_{j=1}^{m} v_{j}^{2}=1 ; \\
\sum_{j=1}^{m} \sum_{i=1}^{n}\left(\frac{v_{i}^{1}+v_{j}^{2}}{2}\right)+\sum_{j=1}^{n}\left(\frac{v_{c}^{1}+v_{j}^{2}}{2}\right)+\sum_{j=1}^{n}\left(\frac{v_{i}^{1}+v_{c}^{2}}{2}\right), & \sum_{i=1}^{n} v_{i}^{1}<1, \sum_{j=1}^{m} v_{j}^{2}=1 ; \\
\sum_{j=1}^{m} \sum_{i=1}^{n}\left(\frac{v_{i}^{1}+v_{j}^{2}}{2}\right)+\sum_{j=1}^{m}\left(\frac{v_{c}^{1}+v_{j}^{2}}{2}\right)+\sum_{i=1}^{n}\left(\frac{v_{i}^{1}+v_{c}^{2}}{2}\right)+\frac{v_{c}^{1}+v_{c}^{2}}{2}, & \sum_{i=1}^{n} v_{i}^{1}=1, \sum_{j=1}^{m} v_{j}^{2}<1 ;
\end{array} ; \sum_{j=1}^{m} v_{j}^{2}<1,\right.
\end{aligned}
$$


where $v_{c}^{1}=1-\sum_{i=1}^{n} v_{i}^{1}$ and $v_{c}^{2}=1-\sum_{j=1}^{m} v_{j}^{2}$. Note that superscript in the above equations is not exponent when $D$ numbers are more than two.

It must be pointed out that the combination operation defined in Definition 5 does not preserve the associative property. It is clear that $\left(D_{1} \oplus D_{2}\right) \oplus D_{3} \neq D_{1} \oplus\left(D_{2} \oplus\right.$ $\left.D_{3}\right) \neq\left(D_{1} \oplus D_{3}\right) \oplus D_{2}$. In order that multiple $D$ numbers can be combined correctly and efficiently, a combination operation for multiple $D$ numbers is developed as follows.

Definition 6 (multiple $D$ numbers' rule of combination). Let $D_{1}, D_{2}, \ldots, D_{n}$ be $n D$ numbers, $\mu_{j}$ is an order variable for each $D_{j}$, indicated by tuple $\left\langle\mu_{j}, D_{\mu_{j}}\right\rangle$, and then the combination operation of multiple $D$ numbers is a mapping $f_{D}$, such that

$$
f_{D}\left(D_{1}, D_{2}, \ldots, D_{n}\right)=\left[\cdots\left[D_{\lambda_{1}} \oplus D_{\lambda_{2}}\right] \oplus \cdots \oplus D_{\lambda_{n}}\right],
$$

where $D_{\lambda_{i}}$ is $D_{\mu_{j}}$ of the tuple $\left\langle\mu_{j}, D_{\mu_{j}}\right\rangle$ having the $i$ th lowest $\mu_{j}$.

In the meanwhile, an aggregate operation is proposed on this special $D$ numbers, as such.

Definition 7 ( $D$ numbers' integration). For $D=\left\{\left(b_{1}, v_{1}\right),\left(b_{2}\right.\right.$, $\left.\left.v_{2}\right), \ldots,\left(b_{i}, v_{i}\right), \ldots,\left(b_{n}, v_{n}\right)\right\}$, the integrating representation of $D$ is defined as

$$
I(D)=\sum_{i=1}^{n} b_{i} v_{i}
$$

2.3. Distance Function of D Numbers. A new distance function to measure the distance between two $D$ numbers has been proposed in [68].

In $D$ numbers theory, there is no compulsive requirement that the frame of discernment is a mutually exclusive and collectively exhaustive set. So a relative matrix is used to represent the relationship of $D$ numbers. The definition of relation matrix is shown as follows.

\subsubsection{Relative Matrix and Intersection Matrix}

Definition 8. Let $L_{i}$ and $L_{j}$ denote the number $i$ and number $j$ of $n$ linguistic constants, $S_{i j}$ represent the intersection area between $L_{i}$ and $L_{j}$, and $U_{12}$ is the union area between $L_{i}$ and $L_{j}$. The definition of nonexclusive degree $E_{i j}$ can be shown as follows:

$$
E_{i j}=\frac{S_{i j}}{U_{i j}}
$$

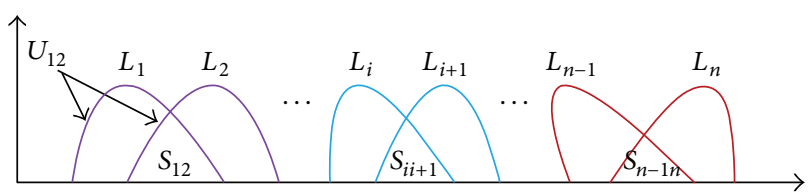

Figure 2: Example for linguistic constants.

Next, the relative matrix can be constructed for these elements based on $E_{i j}$ :

$$
R=\left[\begin{array}{cccccc}
1 & E_{12} & \cdots & E_{1 i} & \cdots & E_{1 n} \\
E_{21} & 1 & \cdots & E_{2 i} & \cdots & E_{2 n} \\
\vdots & \vdots & \cdots & \vdots & \cdots & \vdots \\
E_{i 1} & E_{i 2} & \cdots & 1 & \cdots & E_{\text {in }} \\
\vdots & \vdots & \cdots & \vdots & \cdots & \vdots \\
E_{n 1} & E_{n 2} & \cdots & E_{n i} & \cdots & 1
\end{array}\right] .
$$

For example, suppose there are $n$ linguistic constants which are shown in Figure 2. The nonexclusive degree between two $D$ numbers can be obtained by $E_{i j}$ based on the intersection area $S_{i j}$ and the union area $U_{i j}$ of two linguistic constants $L_{i}$ and $L_{j}$.

Definition 9. After obtaining the relative matrix $R$ between two subsets which belong to $2^{\Omega}$, the definition of the intersection degree of two subsets can be shown as follows:

$$
I\left(S_{1}, S_{2}\right)=\frac{\sum E_{i j}}{\left|S_{1}\right| \cdot\left|S_{2}\right|},
$$

where $i \neq j$ and $S_{1}, S_{2} \in 2^{\Omega}$. $i$ denotes the first element's row number of set $S_{1}$ in the relative matrix $R$ and $j$ is the first element's column number of set $S_{2}$. $\left|S_{1}\right|$ expresses the cardinality of $S_{1}$ and $\left|S_{2}\right|$ represents the cardinality of $S_{2}$. In particular, when $i=j, I=1$.

2.3.2. Distance between Two D Numbers. It is known that $D$ numbers theory is a generalization of the Dempster-Shafer theory. The body of $D$ numbers can be considered as a discrete random variable whose values are $2^{\Omega}$ by a probability distribution $d$. Therefore, $D$ number can be seen as a vector $\vec{d}$ in the vector space. Thus, the distance function between two $D$ numbers can be defined as follows.

Definition 10. Let $d_{1}$ and $d_{2}$ be two $D$ numbers on the same frame of discernment $\Omega$, containing $N$ elements which are not required to be exclusive to each other. The distance between $d_{1}$ and $d_{2}$ is

$$
d_{D-\operatorname{number}\left(d_{1}, d_{2}\right)}=\sqrt{\frac{1}{2}\left(\overrightarrow{d_{1}}-\overrightarrow{d_{2}}\right)^{T} \underline{\underline{D}} \cdot \underline{\underline{I}}\left(\overrightarrow{d_{1}}-\overrightarrow{d_{2}}\right)},
$$

where $\underline{\underline{D}}$ and $\underline{\underline{I}}$ are two $\left(2^{N} \times 2^{N}\right)$-dimensional matrixes. 
The elements of $\underline{\underline{D}}$ can be represented as

$$
D(A, B)=\frac{|A \cap B|}{|A \cup B|}, \quad\left(A, B \in 2^{\Omega}\right) .
$$

The elements of $\underline{\underline{I}}$ can be denoted as

$$
\begin{aligned}
I(A, B)= & \frac{\sum E_{i j}}{|A| \cdot|B|}, \\
& (i \neq j),\left(A, B \in 2^{\Omega}\right),(\text { when } i=j, I=1),
\end{aligned}
$$

where $i$ denotes the first element's row number of set $S_{1}$ in the relative matrix $R$ and $j$ is the first element's column number of set $S_{2}$.

2.4. TOPSIS Method. Technique for order preference by similarity to ideal solution (TOPSIS), which is proposed in [19], is a ranking method which is applied to MCDM problem. The standard TOPSIS method is designed to find alternatives which have the shortest distance from the positive ideal solution and the longest distance from the negative ideal solution. The positive ideal solution attempts to seek the maximization of benefit criteria and the minimum of the cost criteria, whereas the negative ideal solution is just the opposite.

Definition 11. Construct a decision matrix $D=\left(x_{m n}\right)$, which includes alternatives and criteria. Normalize the decision matrix

$$
r_{i j}=\frac{x_{i j}}{\sqrt{\sum_{j=1}^{m} x_{i j}^{2}}}, \quad i=1, \ldots, m ; j=1, \ldots, n .
$$

To obtain the weighted decision matrix using the associated weights to multiply the columns of the normalized decision matrix $A=v(m n)$,

$$
v_{i j}=w_{j} \times r_{i j}, \quad i=1, \ldots, m ; j=1, \ldots, n,
$$

where $w_{j}$ is the weight of $j$ th criterion.

Determine the positive ideal and negative ideal solutions. The definitions of the positive ideal solution, represented as $A^{+}$, and the negative ideal solution, represented as $A^{-}$, are shown as follows:

$$
\begin{aligned}
A^{+} & =\left\{v_{1}^{+}, v_{2}^{+}, \ldots, v_{n}^{+}\right\} \\
& =\left\{\left(\max _{i} v_{i j} \mid j \in K_{b}\right)\left(\min _{i} v_{i j} \mid j \in K_{c}\right)\right\} \\
A^{-} & =\left\{v_{1}^{-}, v_{2}^{-}, \ldots, v_{n}^{-}\right\} \\
& =\left\{\left(\min _{i} v_{i j} \mid j \in K_{b}\right)\left(\max _{i} v_{i j} \mid j \in K_{c}\right)\right\},
\end{aligned}
$$

where $K_{b}$ denotes the set of benefit criteria and $K_{c}$ represents the set of cost criteria.

Calculate the separation measures between the existing alternatives and the positive ideal and negative ideal solutions. The separation measures that are determined by
Euclidean distance, $S_{i}^{+}$and $S_{i}^{-}$, of each alternative from the positive ideal and negative ideal solutions, respectively, are shown as

$$
\begin{gathered}
S_{i}^{+}=\sqrt{\sum_{j=1}^{n}\left(v_{j}^{+}-v_{i j}\right)^{2}}, \quad i=1, \ldots, m ; j=1, \ldots, n, \\
S_{i}^{-}=\sqrt{\sum_{j=1}^{n}\left(v_{j}^{-}-v_{i j}\right)^{2}}, \quad i=1, \ldots, m ; j=1, \ldots, n .
\end{gathered}
$$

Obtain the relative closeness to the ideal solution:

$$
C_{i}=\frac{S_{i}^{-}}{S_{i}^{-}+S_{i}^{+}}, \quad i=1, \ldots, m .
$$

Sort the alternatives based on the relative closeness to the ideal solution. If alternatives have higher $C_{i}$, it will be more significant and should be assigned higher priority.

\section{The Modified TOPSIS Method Based on $D$ Numbers}

TOPSIS is an effective methodology to handle the problem in multicriteria decision-making. $D$ numbers theory is a new representation of uncertain information, which can denote the more fuzzy conditions. So the combination of TOPSIS and $D$ numbers is a new experiment to make decisions in an uncertain environment. Next, we will propose the modified TOPSIS method named D-TOPSIS to deal with some Gordian knots in MCDM.

\subsection{Construct the Decision Matrix}

Definition 12. Suppose there is a matrix $D=\left(x_{m n}\right)$, which is constructed by alternatives and criteria.

Obtain the weight for each criterion of the matrix, and assign the weight to corresponding criterion to determine the weighted matrix $A=v(m n)$ :

$$
v_{i j}=w_{j} \times x_{i j}, \quad i=1, \ldots, m ; j=1, \ldots, n,
$$

where $w_{j}$ is the weight for $j$ criterion. Normalize the matrix to get the decision matrix:

$$
d_{i j}=\frac{v_{i j}}{\sqrt{\sum_{j=1}^{m} v_{i j}^{2}}}, \quad i=1, \ldots, m ; j=1, \ldots, n .
$$

3.2. Determine D Numbers and Define Interrelation between Their Elements. In Section 3.1, the decision matrix has been constructed; then it will be transformed to $D$ numbers as

$$
\left[\begin{array}{cccc}
d_{1}(\{1\})=d_{11} & d_{1}(\{2\})=d_{12} & \cdots & d_{1}(\{n\})=d_{1 n} \\
d_{2}(\{1\})=d_{21} & d_{2}(\{2\})=d_{22} & \cdots & d_{2}(\{n\})=d_{2 n} \\
\ddots & \vdots & \\
d_{m}(\{1\})=d_{m 1} & d_{m}(\{2\})=d_{m 2} & \cdots & d_{m}(\{n\})=d_{m n}
\end{array}\right] .
$$


The interrelation between criteria is considered in the $D$-TOPSIS method for more reasonable and more effective decision-making, which is defined as follows.

Definition 13. Let $I_{i j}$ denote the influence relation from criterion $i$ to criterion $j$. Let $S_{i j}$ represent the interrelation between criterion $i$ and criterion $j$, which can also be seen as the intersection of criterion $i$ and criterion $j$. Then, one gives the definition of $S$ based on $I$ shown as follows:

$$
S_{i j}=S_{j i}=\frac{1}{2} \times\left(I_{i j}+I_{j i}\right) .
$$

Definition 14. Let $U_{i j}$ denote the union set between criterion $i$ and criterion $j$. Let $W_{i}$ represent the weight of criterion $i$ from the comprehensive views of four experts. Then, one determines the definition of $U$ based on $I$ and weights of criterion $i$ and criterion $j$ shown as follows:

$$
U_{i j}=U_{j i}=W_{i}+W_{j}-I_{i j}
$$

3.3. The Methodology for Proposed D-TOPSIS. Firstly, determine the positive ideal and negative ideal solutions. The positive ideal solution, denoted as $D A^{+}$, and the negative ideal solution, denoted as $D A^{-}$, are defined as follows:

$$
\begin{aligned}
D \_A^{+} & =\left\{d_{1}^{+}, d_{2}^{+}, \ldots, d_{n}^{+}\right\} \\
& =\left\{\left(\max _{i} d_{i j} \mid j \in K_{b}\right)\left(\min _{i} d_{i j} \mid j \in K_{c}\right)\right\}, \\
D \_A^{-} & =\left\{d_{1}^{-}, d_{2}^{-}, \ldots, d_{n}^{-}\right\} \\
& =\left\{\left(\min _{i} d_{i j} \mid j \in K_{b}\right)\left(\max _{i} d_{i j} \mid j \in K_{c}\right)\right\},
\end{aligned}
$$

where $K_{b}$ is the set of benefit criteria and $K_{c}$ is the set of cost criteria.

Secondly, obtain the separation measures of the existing alternatives from the positive ideal and negative ideal solutions. The separation measures based on the distance function of $D$ numbers, $D_{-} S_{i}^{+}$and $D_{-} S_{i}^{-}$, of each alternative from the positive ideal and negative ideal solutions, respectively, are derived from

$$
\begin{gathered}
D S_{i}^{+}=\sqrt{\sum_{j=1}^{n} \frac{1}{2}\left(\overrightarrow{d_{j}^{+}}-\overrightarrow{d_{i j}}\right)^{T} \underline{\underline{D}} \cdot \underline{\underline{I}}\left(\overrightarrow{d_{j}^{+}}-\overrightarrow{d_{i j}}\right),} \\
i=1, \ldots, m ; j=1, \ldots, n, \\
D S_{i}^{-}=\sqrt{\sum_{j=1}^{n} \frac{1}{2}\left(\overrightarrow{d_{j}^{-}}-\overrightarrow{d_{i j}}\right)^{T} \underline{\underline{D}} \cdot \underline{\underline{I}}\left(\overrightarrow{d_{j}^{-}}-\overrightarrow{d_{i j}}\right)}, \\
i=1, \ldots, m ; j=1, \ldots, n .
\end{gathered}
$$
tion:

Finally, calculate the relative closeness to the ideal solu-

$$
D \_C_{i}=\frac{D S_{i}^{-}}{D \_S_{i}^{-}+D \_S_{i}^{+}}, \quad i=1, \ldots, m .
$$

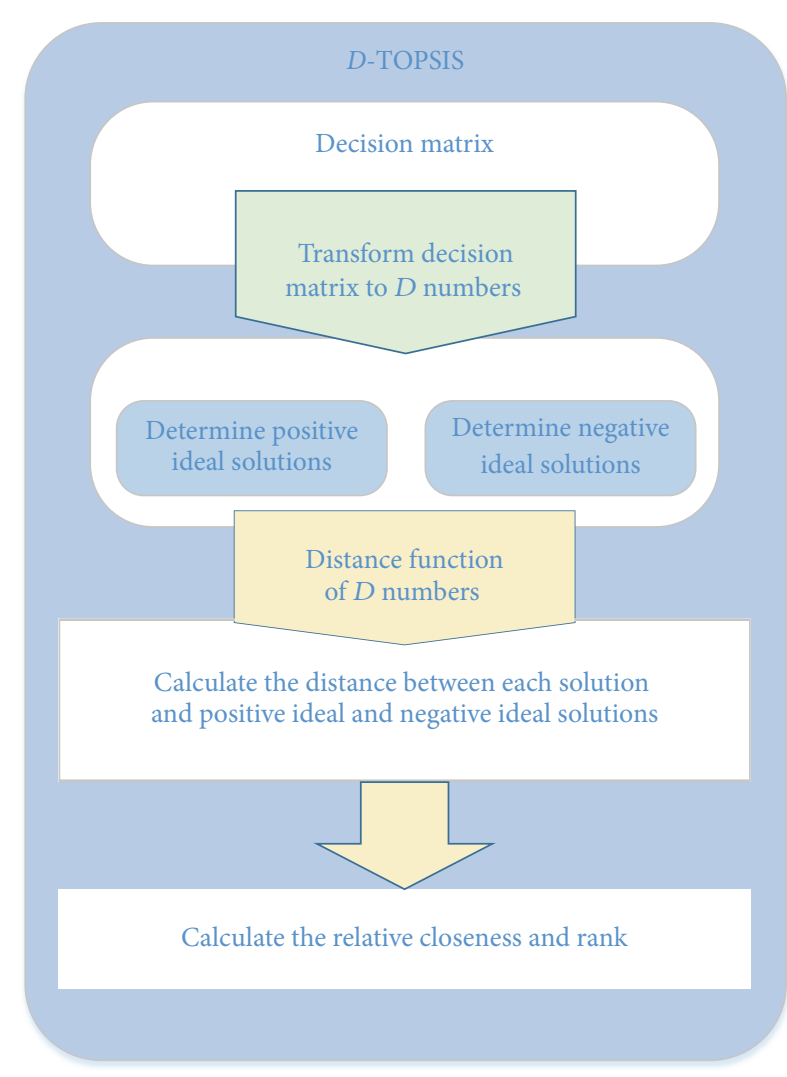

Figure 3: The flow chart of $D$-TOPSIS.

Rank the alternatives according to the relative closeness to the ideal solution: the alternatives with higher $D_{-} C_{i}$ are assumed to be more important and should be given higher priority. The flow chart of $D$-TOPSIS is shown in Figure 3.

\section{An Application for Human Resources Selection Based on D-TOPSIS}

An import and export trading company plans to recruit a department manager who must satisfy their various requirements [69]. There are some relevant test items provided by the human resources department of the company for selecting the best candidate. The test items include two great aspects: the objective and the subjective aspects. In addition, the objective aspect is divided into two sides. The first one is knowledge test which includes language test, professional test, and safety rule test. The other one is skill test which has the items of professional skills and computer skills. The subjective aspect is determined by the corresponding interviews including panel interview and 1-on-1 interview. Now, 17 candidates are qualified for the test, and four experts rate all the candidates in interviews. The test results for objective and subjective attributes are shown in Tables 1 and 2. What is more, the weights of all the items from four experts are also shown in Table 3.

The flow chart of the process to select the best candidate is shown in Figure 4. Next, we will illustrate the specific steps 
TABLE 1: The scores of the objective aspects.

\begin{tabular}{|c|c|c|c|c|c|c|}
\hline \multirow{3}{*}{ Number } & \multirow{3}{*}{ Candidates } & \multicolumn{5}{|c|}{ Objective attributes } \\
\hline & & \multicolumn{3}{|c|}{ Knowledge test } & \multicolumn{2}{|c|}{ Skill test } \\
\hline & & Language test & Professional test & Safety rule test & Professional skills & Computer skills \\
\hline 1 & James B. Wang & 80 & 70 & 87 & 77 & 76 \\
\hline 2 & Carol L. Lee & 85 & 65 & 76 & 80 & 75 \\
\hline 3 & Kenney C. Wu & 78 & 90 & 72 & 80 & 85 \\
\hline 4 & Robert M. Liang & 75 & 84 & 69 & 85 & 65 \\
\hline 5 & Sophia M. Cheng & 84 & 67 & 60 & 75 & 85 \\
\hline 6 & Lily M. Pai & 85 & 78 & 82 & 81 & 79 \\
\hline 7 & Abon C. Hsieh & 77 & 83 & 74 & 70 & 71 \\
\hline 8 & Frank K. Yang & 78 & 82 & 72 & 80 & 78 \\
\hline 9 & Ted C. Yang & 85 & 90 & 80 & 88 & 90 \\
\hline 10 & Sue B. Ho & 89 & 75 & 79 & 67 & 77 \\
\hline 11 & Vincent C. Chen & 65 & 55 & 68 & 62 & 70 \\
\hline 12 & Rosemary I. Lin & 70 & 64 & 65 & 65 & 60 \\
\hline 13 & Ruby J. Huang & 95 & 80 & 70 & 75 & 70 \\
\hline 14 & George K. Wu & 70 & 80 & 79 & 80 & 85 \\
\hline 15 & Philip C. Tsai & 60 & 78 & 87 & 70 & 66 \\
\hline 16 & Michael S. Liao & 92 & 85 & 88 & 90 & 85 \\
\hline 17 & Michelle C. Lin & 86 & 87 & 80 & 70 & 72 \\
\hline
\end{tabular}

TABLE 2: The scores of the subjective aspects from different experts for interview.

\begin{tabular}{|c|c|c|c|c|c|c|c|c|}
\hline \multirow{3}{*}{ Number } & \multicolumn{8}{|c|}{ Subjective attributes } \\
\hline & \multicolumn{2}{|c|}{ Expert 1} & \multicolumn{2}{|c|}{ Expert 2} & \multicolumn{2}{|c|}{ Expert 3} & \multicolumn{2}{|c|}{ Expert 4} \\
\hline & Panel & 1-on-1 & Panel & 1-on-1 & Panel & 1-on-1 & Panel & 1-on-1 \\
\hline 1 & 80 & 75 & 85 & 80 & 75 & 70 & 90 & 85 \\
\hline 2 & 65 & 75 & 60 & 70 & 70 & 77 & 60 & 70 \\
\hline 3 & 90 & 85 & 80 & 85 & 80 & 90 & 90 & 95 \\
\hline 4 & 65 & 70 & 55 & 60 & 68 & 72 & 62 & 72 \\
\hline 5 & 75 & 80 & 75 & 80 & 50 & 55 & 70 & 75 \\
\hline 6 & 80 & 80 & 75 & 85 & 77 & 82 & 75 & 75 \\
\hline 7 & 65 & 70 & 70 & 60 & 65 & 72 & 67 & 75 \\
\hline 8 & 70 & 60 & 75 & 65 & 75 & 67 & 82 & 85 \\
\hline 9 & 80 & 85 & 95 & 85 & 90 & 85 & 90 & 92 \\
\hline 10 & 70 & 75 & 75 & 80 & 68 & 78 & 65 & 70 \\
\hline 11 & 50 & 60 & 62 & 65 & 60 & 65 & 65 & 70 \\
\hline 12 & 60 & 65 & 65 & 75 & 50 & 60 & 45 & 50 \\
\hline 13 & 75 & 75 & 80 & 80 & 65 & 75 & 70 & 75 \\
\hline 14 & 80 & 70 & 75 & 72 & 80 & 70 & 75 & 75 \\
\hline 15 & 70 & 65 & 75 & 70 & 65 & 70 & 60 & 65 \\
\hline 16 & 90 & 95 & 92 & 90 & 85 & 80 & 88 & 90 \\
\hline 17 & 80 & 85 & 70 & 75 & 75 & 80 & 70 & 75 \\
\hline
\end{tabular}


TABLE 3: Weight for different test items from different experts.

\begin{tabular}{|c|c|c|c|c|c|}
\hline \multirow{2}{*}{ Number } & \multirow{2}{*}{ Attributes } & \multicolumn{4}{|c|}{ Weight } \\
\hline & & Expert 1 & Expert 2 & Expert 3 & Expert 4 \\
\hline 1 & Language test & 0.066 & 0.042 & 0.060 & 0.047 \\
\hline 2 & Professional test & 0.196 & 0.112 & 0.134 & 0.109 \\
\hline 3 & Safety rule test & 0.066 & 0.082 & 0.051 & 0.037 \\
\hline 4 & Professional skills & 0.130 & 0.176 & 0.167 & 0.133 \\
\hline 5 & Computer skills & 0.130 & 0.118 & 0.100 & 0.081 \\
\hline 6 & Panel interview & 0.216 & 0.215 & 0.203 & 0.267 \\
\hline 7 & 1-on-1 interview & 0.196 & 0.255 & 0.285 & 0.326 \\
\hline
\end{tabular}

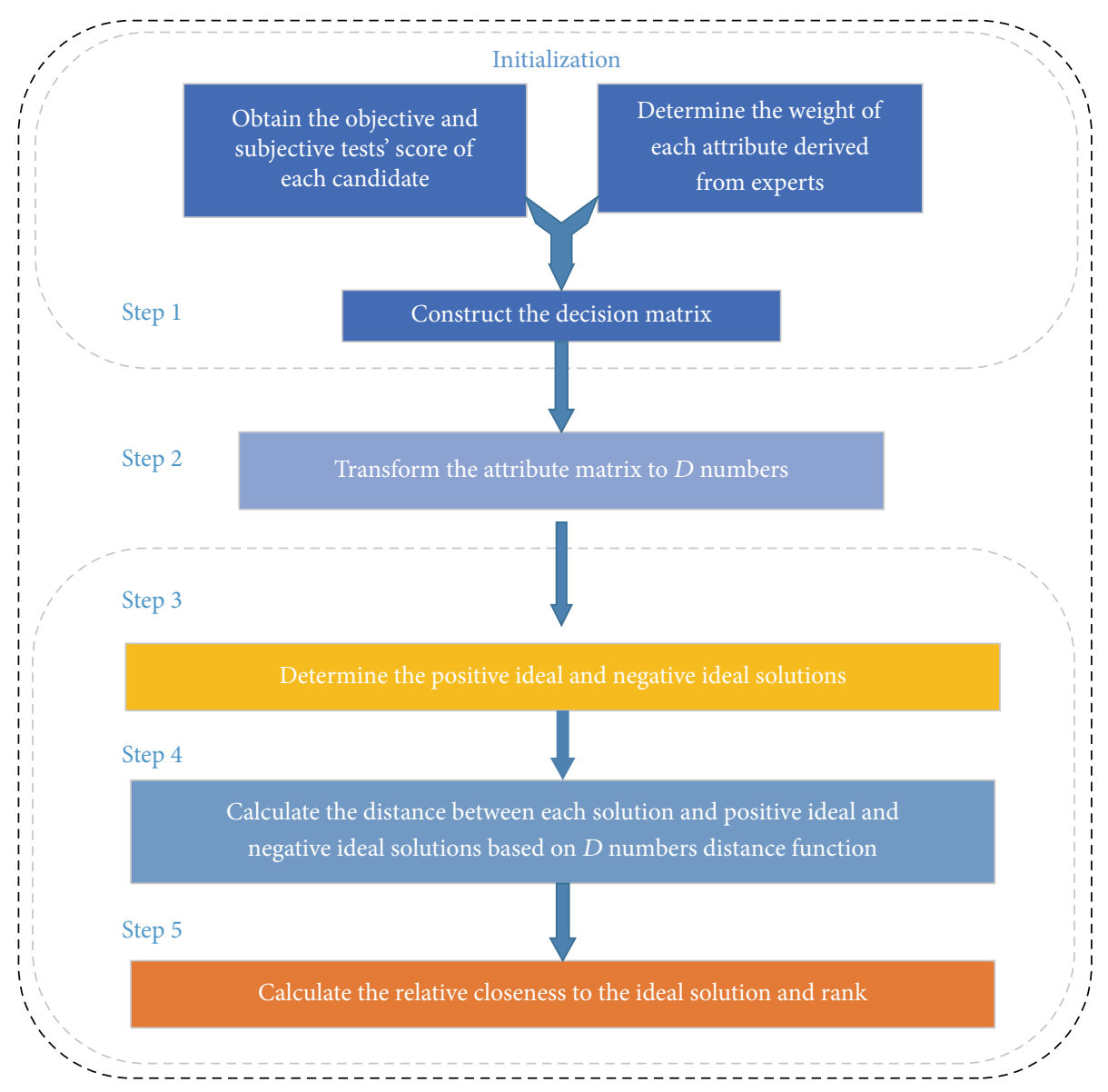

FIGURE 4: The flow chart of human resources selection.

about how to select the best one from the 17 candidates for the company using the new proposed $D$-TOPSIS method.

Step 1. Construct the attribute matrix.

Firstly, we calculate the comprehensive scores of each candidate combining the four experts' advice in the interviews. And the results are shown in Table 4.

Then, we can obtain the weighted overall results of this test from the objective and subjective aspects based on Tables
1,3 , and 4 , which is shown in Table 5 and can be seen as the decision matrix.

Step 2. Transform decision matrix to $D$ numbers and obtain the interrelation between these criteria.

From Step 1, the decision matrix has be determined. Now, we need to transform the matrix to $D$ numbers. Firstly, normalize the decision matrix for each item of each candidate shown in Table 6. We will represent each test item using $a, b$, 
TABLE 4: The comprehensive scores from different experts for the interview.

\begin{tabular}{lcc}
\hline \multirow{2}{*}{ Number } & \multicolumn{2}{c}{ Subjective attributes } \\
\hline 1 & Panel interview & 1-on-1 interview \\
2 & 82.5 & 77.5 \\
3 & 63.75 & 73 \\
4 & 85 & 88.75 \\
5 & 62.5 & 68.5 \\
6 & 67.5 & 72.5 \\
7 & 76.75 & 80.5 \\
8 & 66.75 & 69.25 \\
9 & 75.5 & 69.25 \\
10 & 88.75 & 86.75 \\
11 & 69.5 & 75.75 \\
12 & 59.25 & 65 \\
13 & 55 & 62.5 \\
14 & 72.5 & 76.25 \\
15 & 77.5 & 71.75 \\
16 & 67.5 & 67.5 \\
17 & 88.75 & 88.75 \\
\hline
\end{tabular}

$c, d, e, f$, and $g$ for convenience. The interrelation between 7 different criteria is shown in Table 7.

Then, the union set $U$ and intersection $I$ can be obtained from the experts' scoring and experience and is shown in Table 8 based on Definitions 13 and 14. And, in Figure 5, the interrelation between different criteria can be represented by the network. The different size of each node denotes the weight of different criteria from multiple experts, while the width of the edge reflects the interrelation of the different criteria in some ways.

Step 3. Obtain the positive ideal solutions $D_{-} A^{+}$and negative ideal solutions $D \_A^{-}$based on (30).

We select the positive ideal and negative ideal solutions from Table 6 . The positive ideal solution is determined by the highest score of each attribute; similarly, the negative ideal solution is defined by the lowest score of each attribute. And the results are shown in Table 9.

Step 4. Calculate the distance between each solution and positive ideal and negative ideal solutions based on (31).

From the above steps, the positive ideal solutions $D_{-} A^{+}$ and negative ideal solutions $D A^{-}$have been obtained. Next, we will calculate the distance from each alternative scheme to $D A^{+}$and $D A^{-}$by (17), respectively. The results are shown in Table 10.

Step 5. Calculate the relative closeness and rank.

In this step, we calculate the relative closeness to the ideal solution of each attribute by (32). Finally, sort each candidate

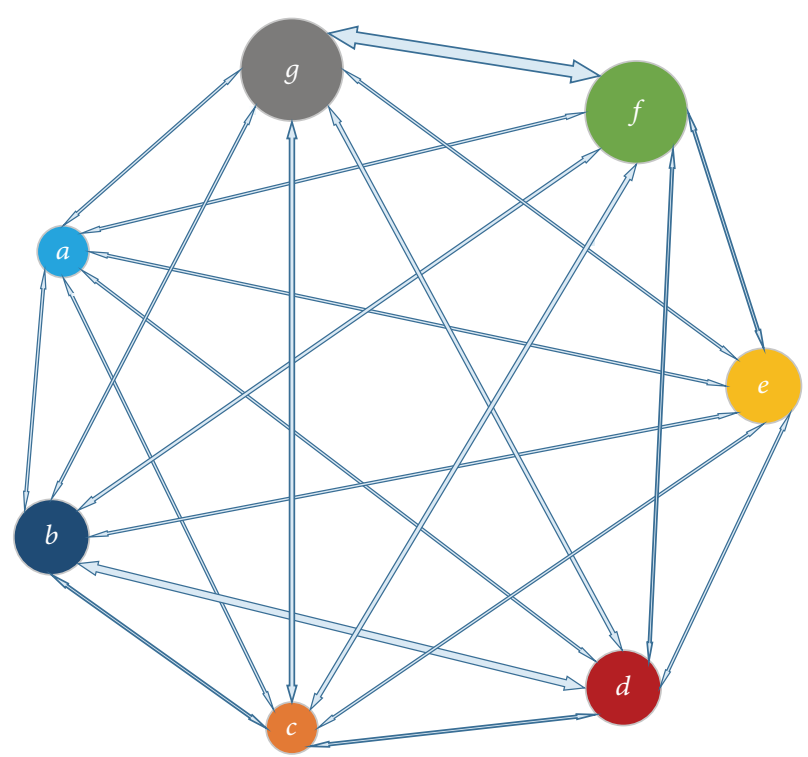

Figure 5: The network chart of interrelation between different criteria.

by the closeness values. The distances and ranking results are shown in Table 10.

The best candidate can be selected easily based on the ranking results. It is worth noting that the ranking results will be different depending on two factors: (1) the scores in objective and subjective tests of each criterion and (2) the interrelation and weights among different criteria. And the major advantages of $D$-TOPSIS are reflected in two aspects. Firstly, it can keep the validity of the traditional TOPSIS method. In addition, the relationship between multiattributes is considered for the more reasonable results. The effectiveness of $D$-TOPSIS can be demonstrated by the application.

\section{Conclusion}

In this paper, a new TOPSIS method called D-TOPSIS is proposed to handle MCDM problem using $D$ numbers to extend the classical TOPSIS method. In the proposed method, the decision matrix determination from MCDM problem can be transformed to $D$ numbers, which can effectively represent the inevitable uncertainty, such as incompleteness and imprecision due to the subjective assessment of human beings. And the relationship between multiattributes is considered in the process of decisionmaking, which is more grounded in reality. An example of human resources selection is conducted and illustrates the effectiveness of the proposed D-TOPSIS method. In future research, the theoretical framework of the $D$-TOPSIS needs to be increasingly perfected. For example, how to scientifically produce the relationship between multicriteria should be further investigated. Also, the proposed method should be utilized in other applications to further verify its effectiveness. 
TABLE 5: The weighted overall scores of the test.

\begin{tabular}{|c|c|c|c|c|c|c|c|}
\hline \multirow{3}{*}{ Number } & \multicolumn{5}{|c|}{ Objective attributes } & \multirow{2}{*}{\multicolumn{2}{|c|}{ Subjective attributes }} \\
\hline & & Knowledge test & & Skill & test & & \\
\hline & Language test & Professional test & Safety rule test & Professional skills & Computer skills & Panel interview & 1-on-1 interview \\
\hline 1 & 4.3040 & 9.6460 & 5.1330 & 11.6655 & 8.1472 & 18.5790 & 20.5763 \\
\hline 2 & 4.5730 & 8.9570 & 4.4840 & 12.1200 & 8.0400 & 14.3565 & 19.3815 \\
\hline 3 & 4.1964 & 12.4020 & 4.2480 & 12.1200 & 9.1120 & 19.1420 & 23.5631 \\
\hline 4 & 4.0350 & 11.5752 & 4.0710 & 12.8775 & 6.9680 & 14.0750 & 18.1868 \\
\hline 5 & 4.5192 & 9.2326 & 3.5400 & 11.3625 & 9.1120 & 15.2010 & 19.2488 \\
\hline 6 & 4.5730 & 10.7484 & 4.8380 & 12.2715 & 8.4688 & 17.2841 & 21.3728 \\
\hline 7 & 4.1426 & 11.4374 & 4.3660 & 10.6050 & 7.1662 & 15.0321 & 18.3859 \\
\hline 8 & 4.1964 & 11.2996 & 4.2480 & 12.1200 & 8.3616 & 17.0026 & 18.3859 \\
\hline 9 & 4.5730 & 12.4020 & 4.7200 & 13.3320 & 9.6480 & 19.9865 & 23.0321 \\
\hline 10 & 4.7882 & 10.3350 & 4.6610 & 10.1505 & 8.2544 & 15.6514 & 20.1116 \\
\hline 11 & 3.4970 & 7.5790 & 4.0120 & 9.3930 & 7.5040 & 13.3431 & 17.2575 \\
\hline 12 & 3.7660 & 8.8192 & 3.8350 & 9.8475 & 6.4320 & 12.3860 & 16.5938 \\
\hline 13 & 5.1110 & 11.0240 & 4.1300 & 11.3625 & 7.5040 & 16.3270 & 20.2444 \\
\hline 14 & 3.7660 & 11.0240 & 4.6610 & 12.1200 & 9.1120 & 17.4530 & 19.0496 \\
\hline 15 & 3.2280 & 10.7484 & 5.1330 & 10.6050 & 7.0752 & 15.2010 & 11.9213 \\
\hline 16 & 4.9496 & 11.7130 & 5.1920 & 13.6350 & 9.1120 & 19.9865 & 23.5631 \\
\hline 17 & 4.6268 & 11.9886 & 4.7200 & 10.6050 & 7.7184 & 16.6085 & 20.9081 \\
\hline
\end{tabular}

TABle 6: Constructing $D$ numbers of each candidate.

\begin{tabular}{|c|c|c|c|c|c|c|c|}
\hline Number & Language test & Professional test & Safety rule test & Professional skills & Computer skills & Panel interview & 1-on-1 interview \\
\hline 1 & 0.0551 & 0.1236 & 0.0658 & 0.1495 & 0.1044 & 0.2380 & 0.2636 \\
\hline 2 & 0.0636 & 0.1246 & 0.0624 & 0.1685 & 0.1118 & 0.1996 & 0.2695 \\
\hline 3 & 0.0495 & 0.1463 & 0.0501 & 0.1430 & 0.1075 & 0.2258 & 0.2779 \\
\hline 4 & 0.0562 & 0.1612 & 0.0567 & 0.1794 & 0.0971 & 0.1961 & 0.2533 \\
\hline 5 & 0.0626 & 0.1278 & 0.0490 & 0.1573 & 0.1262 & 0.2105 & 0.2665 \\
\hline 6 & 0.0575 & 0.1351 & 0.0608 & 0.1542 & 0.1064 & 0.2173 & 0.2686 \\
\hline 7 & 0.0582 & 0.1608 & 0.0614 & 0.1491 & 0.1007 & 0.2113 & 0.2585 \\
\hline 8 & 0.0555 & 0.1494 & 0.0562 & 0.1603 & 0.1106 & 0.2249 & 0.2432 \\
\hline 9 & 0.0521 & 0.1414 & 0.0538 & 0.1520 & 0.1100 & 0.2279 & 0.2626 \\
\hline 10 & 0.0647 & 0.1398 & 0.0630 & 0.1373 & 0.1116 & 0.2116 & 0.2720 \\
\hline 11 & 0.0559 & 0.1211 & 0.0641 & 0.1501 & 0.1199 & 0.2132 & 0.2757 \\
\hline 12 & 0.0611 & 0.1430 & 0.0622 & 0.1597 & 0.1043 & 0.2008 & 0.2690 \\
\hline 13 & 0.0675 & 0.1456 & 0.0546 & 0.1501 & 0.0991 & 0.2157 & 0.2674 \\
\hline 14 & 0.0488 & 0.1428 & 0.0604 & 0.1570 & 0.1181 & 0.2261 & 0.2468 \\
\hline 15 & 0.0505 & 0.1682 & 0.0803 & 0.1659 & 0.1107 & 0.2378 & 0.1865 \\
\hline 16 & 0.0561 & 0.1329 & 0.0589 & 0.1547 & 0.1034 & 0.2267 & 0.2673 \\
\hline 17 & 0.0600 & 0.1553 & 0.0612 & 0.1374 & 0.1000 & 0.2152 & 0.2709 \\
\hline
\end{tabular}

TABLE 7: The interrelation between 7 different criteria.

\begin{tabular}{lccccccc}
\hline Relation & $a$ & $b$ & $c$ & $d$ & $e$ & $f$ & $g$ \\
\hline$a$ & 0 & 0.1 & 0.1 & 0.1 & 0.2 & 0.3 & 0.2 \\
$b$ & 0.05 & 0 & 0 & 0.4 & 0.05 & 0.3 & 0.2 \\
$c$ & 0 & 0.1 & 0 & 0.1 & 0 & 0.4 & 0.4 \\
$d$ & 0 & 0.2 & 0 & 0 & 0.1 & 0.4 & 0.3 \\
$e$ & 0 & 0.15 & 0.1 & 0.15 & 0 & 0.3 & 0.3 \\
$f$ & 0 & 0.1 & 0 & 0.1 & 0 & 0 & 0.8 \\
$g$ & 0 & 0.1 & 0 & 0.1 & 0 & 0.8 & 0 \\
\hline
\end{tabular}

TABLE 8: The union set and intersection between different criteria.

\begin{tabular}{cccccccc}
\hline \multirow{2}{*}{$U_{i j}$} & \multicolumn{7}{c}{$S_{i j}$} \\
& $a$ & $b$ & $c$ & $d$ & $e$ & $f$ & $g$ \\
\hline$a$ & 0 & 0.075 & 0.050 & 0.050 & 0.100 & 0.150 & 0.100 \\
$b$ & 1.841 & 0 & 0.050 & 0.300 & 0.100 & 0.200 & 0.150 \\
$c$ & 1.078 & 1.918 & 0 & 0.050 & 0.050 & 0.200 & 0.200 \\
$d$ & 2.003 & 2.593 & 2.055 & 0 & 0.125 & 0.250 & 0.200 \\
$e$ & 1.510 & 2.350 & 1.612 & 2.462 & 0 & 0.150 & 0.150 \\
$f$ & 2.641 & 3.413 & 2.643 & 3.518 & 3.175 & 0 & 0.800 \\
$g$ & 3.093 & 3.883 & 3.045 & 3.970 & 3.577 & 4.108 & 0 \\
\hline
\end{tabular}


TABLE 9: The positive ideal solutions $D \_A^{+}$and negative ideal solutions $D \_A^{-}$.

\begin{tabular}{lccccccc}
\hline Ideal solution Language test & Professional test & Safety rule test & Professional skills & Computer skills & Panel interview & 1-on-1 interview \\
\hline$D \_A^{+}$ & 0.0675 & 0.1682 & 0.0803 & 0.1794 & 0.1262 & 0.2380 & 0.2779 \\
$D \_A^{-}$ & 0.0488 & 0.1211 & 0.0490 & 0.1373 & 0.0971 & 0.1961 & 0.1865 \\
\hline
\end{tabular}

TABLE 10: The relative closeness and ranking results by $D$-TOPSIS method.

\begin{tabular}{lcccc}
\hline Number & $D_{-} S_{i}^{+}$ & $D_{-} S_{i}^{-}$ & $D_{-} C_{i}$ & Rank \\
\hline 1 & 0.0486 & 0.0713 & 0.5943 & 8 \\
2 & 0.0500 & 0.0687 & 0.5787 & 13 \\
3 & 0.0464 & 0.0762 & 0.6215 & 1 \\
4 & 0.0500 & 0.0671 & 0.5730 & 16 \\
5 & 0.0497 & 0.0682 & 0.5783 & 14 \\
6 & 0.0449 & 0.0686 & 0.6047 & 4 \\
7 & 0.0454 & 0.0658 & 0.5919 & 9 \\
8 & 0.0446 & 0.0602 & 0.5744 & 15 \\
9 & 0.0439 & 0.0682 & 0.6085 & 2 \\
10 & 0.0489 & 0.0700 & 0.5885 & 11 \\
11 & 0.0502 & 0.0725 & 0.5909 & 10 \\
12 & 0.0463 & 0.0679 & 0.5946 & 7 \\
13 & 0.0462 & 0.0687 & 0.5980 & 6 \\
14 & 0.0445 & 0.0616 & 0.5802 & 12 \\
15 & 0.0689 & 0.0599 & 0.4651 & 17 \\
16 & 0.0450 & 0.0699 & 0.6084 & 3 \\
17 & 0.0473 & 0.0715 & 0.6022 & 5 \\
\hline
\end{tabular}

\section{Competing Interests}

There is no conflict of interests in this paper.

\section{Authors' Contributions}

Yong Deng designed and performed research. Liguo Fei and Yong $\mathrm{Hu}$ wrote the paper. Liguo Fei and Yong Hu performed the computation. Yong Deng, Liguo Fei, Fuyuan Xiao, and Luyuan Chen analyzed the data. All authors discussed the results and commented on the paper. Liguo Fei and Yong $\mathrm{Hu}$ contributed equally to this work.

\section{Acknowledgments}

The work is partially supported by National Natural Science Foundation of China (Grant nos. 61174022, 61573290, and 61503237) and China State Key Laboratory of Virtual Reality Technology and Systems, Beihang University (Grant no. BUAA-VR-14KF-02).

\section{References}

[1] A. Mardani, A. Jusoh, and E. K. Zavadskas, "Fuzzy multiple criteria decision-making techniques and applicationstwo decades review from 1994 to 2014," Expert Systems with Applications, vol. 42, no. 8, pp. 4126-4148, 2015.
[2] W. Pedrycz, R. Al-Hmouz, A. Morfeq, and A. S. Balamash, "Building granular fuzzy decision support systems," KnowledgeBased Systems, vol. 58, pp. 3-10, 2014.

[3] S. Bandyopadhyay and R. Bhattacharya, "Finding optimum neighbor for routing based on multi-criteria, multi-agent and fuzzy approach," Journal of Intelligent Manufacturing, vol. 26, no. 1, pp. 25-42, 2013.

[4] S. Yao and W.-Q. Huang, "Induced ordered weighted evidential reasoning approach for multiple attribute decision analysis with uncertainty," International Journal of Intelligent Systems, vol. 29, no. 10, pp. 906-925, 2014.

[5] F. Lolli, A. Ishizaka, R. Gamberini, B. Rimini, and M. Messori, "FlowSort-GDSS-a novel group multi-criteria decision support system for sorting problems with application to FMEA," Expert Systems with Applications, vol. 42, no. 17-18, pp. 63426349, 2015.

[6] J. P. Evans and R. E. Steuer, "A revised simplex method for linear multiple objective programs," Mathematical Programming, vol. 5, no. 1, pp. 54-72, 1973.

[7] P. L. Yu and M. Zeleny, "The set of all nondominated solutions in linear cases and a multicriteria simplex method," Journal of Mathematical Analysis and Applications, vol. 49, no. 2, pp. 430468, 1975.

[8] G. W. Torrance, "Decisions with multiple objectives: preferences and value tradeoffs," Health Services Research, vol. 13, no. 3, p. 328, 1978.

[9] J. Rezaei, "Best-worst multi-criteria decision-making method," Omega, vol. 53, pp. 49-57, 2015.

[10] W. Sałabun, "The characteristic objects method: a new distancebased approach to multicriteria decision-making problems," Journal of Multi-Criteria Decision Analysis, vol. 22, no. 1-2, pp. 37-50, 2015.

[11] E. K. Zavadskas, J. Antucheviciene, S. H. R. Hajiagha, and S. S. Hashemi, "The interval-valued intuitionistic fuzzy MULTIMOORA method for group decision making in engineering," Mathematical Problems in Engineering, vol. 2015, Article ID 560690, 13 pages, 2015.

[12] W. Jiang, Y. Luo, X.-Y. Qin, and J. Zhan, "An improved method to rank generalized fuzzy numbers with different left heights and right heights," Journal of Intelligent and Fuzzy Systems, vol. 28, no. 5, pp. 2343-2355, 2015.

[13] G. Lee, K. S. Jun, and E.-S. Chung, "Robust spatial flood vulnerability assessment for Han River using fuzzy TOPSIS with cut level set," Expert Systems with Applications, vol. 41, no. 2, pp. 644-654, 2014.

[14] D. Liang, W. Pedrycz, D. Liu, and P. Hu, "Three-way decisions based on decision-theoretic rough sets under linguistic assessment with the aid of group decision making," Applied Soft Computing Journal, vol. 29, pp. 256-269, 2015.

[15] B. L. Golden, E. A. Wasil, and P. T. Harker, Analytic Hierarchy Process, vol. 113, Springer, New York, NY, USA, 2003.

[16] H. Nguyen, S. Z. M. Dawal, Y. Nukman, H. Aoyama, K. Case, and Y. Deng, "An integrated approach of fuzzy linguistic 
preference based AHP and fuzzy COPRAS for machine tool evaluation," PLOS ONE, vol. 10, no. 9, article e0133599, 2015.

[17] Y. Deng, "Fuzzy analytical hierarchy process based on canonical representation on fuzzy numbers," Journal of Computational Analysis and Applications, vol. 22, no. 2, pp. 201-228, 2017.

[18] E. K. Zavadskas, J. Antucheviciene, Z. Turskis, and H. Adeli, "Hybrid multiple criteria decision making methods: a review of applications in engineering," Scientia Iranica, vol. 23, no. 1, pp. 1-20, 2016.

[19] C. L. Hwang and K. Yoon, Multiple Attribute Decision Making, Springer, Berlin, Germany, 1981.

[20] S. M. Mousavi, S. A. Torabi, and R. Tavakkoli-Moghaddam, "A hierarchical group decision-making approach for new product selection in a fuzzy environment," Arabian Journal for Science and Engineering, vol. 38, no. 11, pp. 3233-3248, 2013.

[21] Z. Yue, "TOPSIS-based group decision-making methodology in intuitionistic fuzzy setting," Information Sciences, vol. 277, pp. 141-153, 2014.

[22] A. Suder and C. Kahraman, "Minimizing environmental risks using fuzzy topsis: location selection for the itu faculty of management," Human and Ecological Risk Assessment, vol. 21, no. 5, pp. 1326-1340, 2015.

[23] M. H. Ahmadi, M. A. Ahmadi, and S. A. Sadatsakkak, "Thermodynamic analysis and performance optimization of irreversible Carnot refrigerator by using multi-objective evolutionary algorithms (MOEAs)," Renewable and Sustainable Energy Reviews, vol. 51, article 4609, pp. 1055-1070, 2015.

[24] B. Vahdani, S. M. Mousavi, R. Tavakkoli-Moghaddam, and H. Hashemi, "A new design of the elimination and choice translating reality method for multi-criteria group decision-making in an intuitionistic fuzzy environment," Applied Mathematical Modelling, vol. 37, no. 4, pp. 1781-1799, 2013.

[25] M. Xia and Z. Xu, "A novel method for fuzzy multi-criteria decision making," International Journal of Information Technology and Decision Making, vol. 13, no. 3, pp. 497-519, 2014.

[26] K. Khalili-Damghani, S. Sadi-Nezhad, and M. Tavana, "Solving multi-period project selection problems with fuzzy goal programming based on TOPSIS and a fuzzy preference relation," Information Sciences, vol. 252, pp. 42-61, 2013.

[27] Y. Kim, E.-S. Chung, S.-M. Jun, and S. U. Kim, "Prioritizing the best sites for treated wastewater instream use in an urban watershed using fuzzy TOPSIS," Resources, Conservation and Recycling, vol. 73, pp. 23-32, 2013.

[28] E. K. Zavadskas, Z. Turskis, and V. Bagočius, "Multi-criteria selection of a deep-water port in the Eastern Baltic Sea," Applied Soft Computing, vol. 26, pp. 180-192, 2015.

[29] G. Lee, K. S. Jun, and E.-S. Chung, "Group decision-making approach for flood vulnerability identification using the fuzzy VIKOR method," Natural Hazards and Earth System Sciences, vol. 15, no. 4, pp. 863-874, 2015.

[30] S. Dadelo, Z. Turskis, E. K. Zavadskas, and R. Dadeliene, "Multicriteria assessment and ranking system of sport team formation based on objective-measured values of criteria set," Expert Systems with Applications, vol. 41, no. 14, pp. 6106-6113, 2014.

[31] S.-M. Yu, H. Zhou, X.-H. Chen, and J.-Q. Wang, "A multicriteria decision-making method based on Heronian mean operators under a linguistic hesitant fuzzy environment," AsiaPacific Journal of Operational Research, vol. 32, no. 5, article 1550035, Article ID 1550035, 2015.

[32] Y. Deng, "D numbers: theory and applications," Journal of Information and Computational Science, vol. 9, no. 9, pp. 24212428, 2012.
[33] X. Deng, Y. Hu, Y. Deng, and S. Mahadevan, "Supplier selection using AHP methodology extended by D numbers," Expert Systems with Applications, vol. 41, no. 1, pp. 156-167, 2014.

[34] X. Deng, Y. Hu, Y. Deng, and S. Mahadevan, "Environmental impact assessment based on D numbers," Expert Systems with Applications, vol. 41, no. 2, pp. 635-643, 2014.

[35] G. Fan, D. Zhong, F. Yan, and P. Yue, "A hybrid fuzzy evaluation method for curtain grouting efficiency assessment based on an AHP method extended by D numbers," Expert Systems with Applications, vol. 44, pp. 289-303, 2016.

[36] N. Rikhtegar, N. Mansouri, A. A. Oroumieh, A. YazdaniChamzini, E. K. Zavadskas, and S. Kildiene, "Environmental impact assessment based on group decision-making methods in mining projects," Economic Research-Ekonomska Istrazivanja, vol. 27, no. 1, pp. 378-392, 2014.

[37] X. Deng, X. Lu, F. T. S. Chan, R. Sadiq, S. Mahadevan, and Y. Deng, "D-CFPR: D numbers extended consistent fuzzy preference relations," Knowledge-Based Systems, vol. 73, pp. 6168, 2015.

[38] H.-C. Liu, J.-X. You, X.-J. Fan, and Q.-L. Lin, "Failure mode and effects analysis using D numbers and grey relational projection method," Expert Systems with Applications, vol. 41, no. 10, pp. 4670-4679, 2014.

[39] A. P. Dempster, "Upper and lower probabilities induced by a multivalued mapping," Annals of Mathematical Statistics, vol. 38, pp. 325-339, 1967.

[40] G. Shafer, A Mathematical Theory of Evidence, vol. 1, Princeton University Press, Princeton, NJ, USA, 1976.

[41] B. Shen, Y. Liu, and J.-S. Fu, "An integrated model for robust multisensor data fusion," Sensors, vol. 14, no. 10, pp. 1966919686, 2014.

[42] Y. Deng, S. Mahadevan, and D. Zhou, "Vulnerability assessment of physical protection systems: a bio-inspired approach," International Journal of Unconventional Computing, vol. 11, no. 3-4, pp. 227-243, 2015.

[43] G. Kabir, S. Tesfamariam, A. Francisque, and R. Sadiq, "Evaluating risk of water mains failure using a Bayesian belief network model," European Journal of Operational Research, vol. 240, no. 1, pp. 220-234, 2015.

[44] Y. Li, J. Chen, F. Ye, and D. Liu, "The improvement of DS evidence theory and its application in IR/MMW target recognition," Journal of Sensors, vol. 2016, Article ID 1903792, 15 pages, 2016.

[45] W. Jiang, Y. Yang, Y. Luo, and X. Qin, "Determining basic probability assignment based on the improved similarity measures of generalized fuzzy numbers," International Journal of Computers, Communications and Control, vol. 10, no. 3, pp. 333-347, 2015.

[46] W. Jiang, J. Zhan, D. Zhou, and X. Li, "A method to determine generalized basic probability assignment in the open world," Mathematical Problems in Engineering, In press.

[47] W.-B. Du, Y. Gao, C. Liu, Z. Zheng, and Z. Wang, "Adequate is better: particle swarm optimization with limited-information," Applied Mathematics and Computation, vol. 268, pp. 832-838, 2015.

[48] D. Cheng, R.-X. Hao, and Y.-Q. Feng, "Embedding even cycles on folded hypercubes with conditional faulty edges," Information Processing Letters, vol. 115, no. 12, pp. 945-949, 2015.

[49] Y. Deng, "A threat assessment model under uncertain environment," Mathematical Problems in Engineering, vol. 2015, Article ID 878024, 12 pages, 2015. 
[50] O. Basir and X. Yuan, "Engine fault diagnosis based on multisensor information fusion using Dempster-Shafer evidence theory," Information Fusion, vol. 8, no. 4, pp. 379-386, 2007.

[51] W. Jiang, B. Wei, C. Xie, and D. Zhou, "An evidential sensor fusion method in fault diagnosis," Advances in Mechanical Engineering, vol. 8, no. 3, pp. 1-7, 2016.

[52] I. Bloch, "Some aspects of Dempster-Shafer evidence theory for classification of multi-modality medical images taking partial volume effect into account," Pattern Recognition Letters, vol. 17, no. 8, pp. 905-919, 1996.

[53] Y. Deng, Y. Liu, and D. Zhou, "An improved genetic algorithm with initial population strategy for symmetric TSP," Mathematical Problems in Engineering, vol. 2015, Article ID 212794, 6 pages, 2015.

[54] Z.-G. Liu, Q. Pan, and J. Dezert, "A belief classification rule for imprecise data," Applied Intelligence, vol. 40, no. 2, pp. 214-228, 2014.

[55] X. Zhang, Y. Deng, F. T. S. Chan, and S. Mahadevan, "A fuzzy extended analytic network process-based approach for global supplier selection," Applied Intelligence, vol. 43, no. 4, pp. 760772, 2015.

[56] J. Ma, W. Liu, P. Miller, and H. Zhou, "An evidential fusion approach for gender profiling," Information Sciences, vol. 333, pp. 10-20, 2016.

[57] L. Sun, R. P. Srivastava, and T. J. Mock, "An information systems security risk assessment model under the Dempster-Shafer theory of belief functions," Journal of Management Information Systems, vol. 22, no. 4, pp. 109-142, 2006.

[58] W. Jiang, C. Xie, B. Wei, and D. Zhou, "A modified method for risk evaluation in failure modes and effects analysis of aircraft turbine rotor blades," Advances in Mechanical Engineering, vol. 8, no. 4, pp. 1-16, 2016.

[59] H.-C. Liu, L. Liu, and Q.-L. Lin, "Fuzzy failure mode and effects analysis using fuzzy evidential reasoning and belief rule-based methodology," IEEE Transactions on Reliability, vol. 62, no. 1, pp. 23-36, 2013.

[60] Y. Yang and D. Han, "A new distance-based total uncertainty measure in the theory of belief functions," Knowledge-Based Systems, vol. 94, pp. 114-123, 2016.

[61] A. Awasthi and S. S. Chauhan, "Using AHP and DempsterShafer theory for evaluating sustainable transport solutions," Environmental Modelling \& Software, vol. 26, no. 6, pp. 787-796, 2011.

[62] A. Frikha and H. Moalla, "Analytic hierarchy process for multisensor data fusion based on belief function theory," European Journal of Operational Research, vol. 241, no. 1, pp. 133-147, 2015.

[63] X. Su, S. Mahadevan, P. Xu, and Y. Deng, "Dependence Assessment in Human Reliability Analysis Using Evidence Theory and AHP," Risk Analysis, vol. 35, no. 7, pp. 1296-1316, 2015.

[64] Y. Deng, "Generalized evidence theory," Applied Intelligence, vol. 43, no. 3, pp. 530-543, 2015.

[65] W. Jiang, B. Wei, X. Qin, J. Zhan, and Y. Tang, "Sensor data fusion based on a new conflict measure," Mathematical Problems in Engineering, In press.

[66] X. Su, S. Mahadevan, W. Han, and Y. Deng, "Combining dependent bodies of evidence," Applied Intelligence, vol. 44, no. 3, pp. 634-644, 2016.

[67] X. Su, S. Mahadevan, P. Xu, and Y. Deng, "Handling of dependence in Dempster-Shafer theory," International Journal of Intelligent Systems, vol. 30, no. 4, pp. 441-467, 2015.
[68] M. Li, Y. Hu, Q. Zhang, and Y. Deng, "A novel distance function of D numbers and its application in product engineering," Engineering Applications of Artificial Intelligence, vol. 47, pp. 6167, 2016.

[69] H.-S. Shih, H.-J. Shyur, and E. S. Lee, "An extension of TOPSIS for group decision making," Mathematical and Computer Modelling, vol. 45, no. 7-8, pp. 801-813, 2007. 


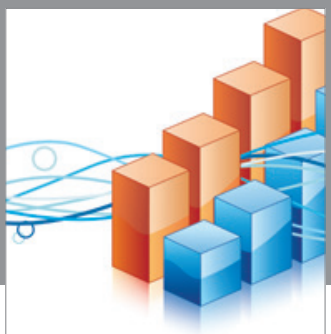

Advances in

Operations Research

vatem alat4

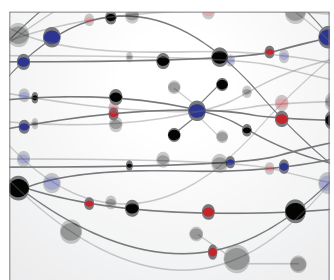

\section{The Scientific} World Journal
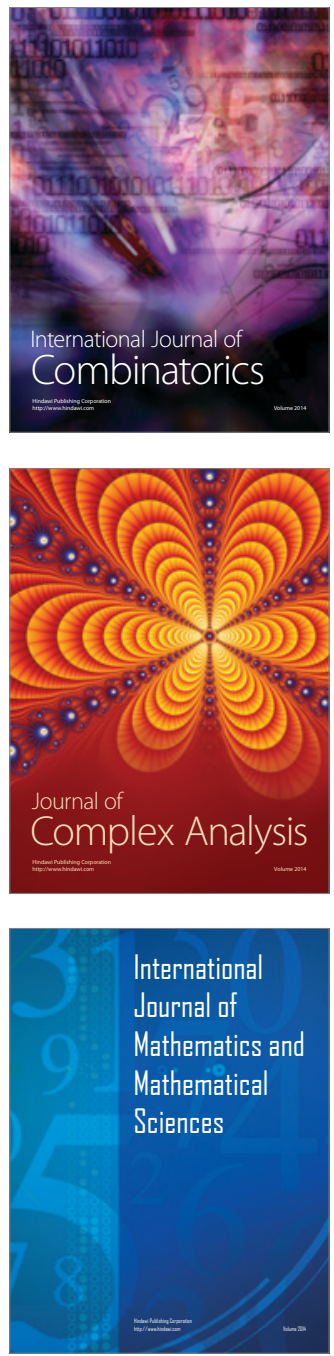
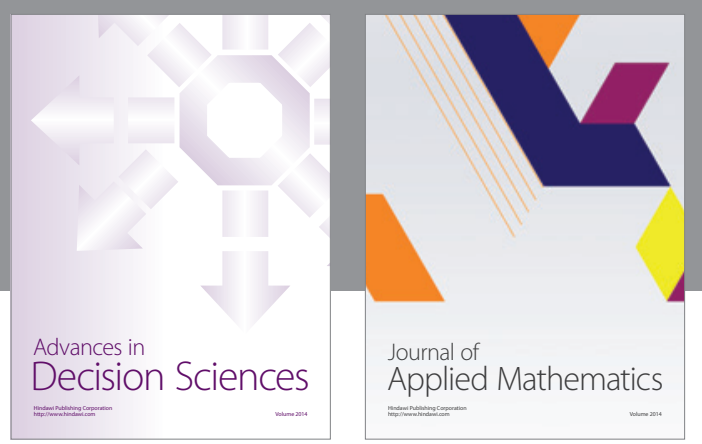

Algebra

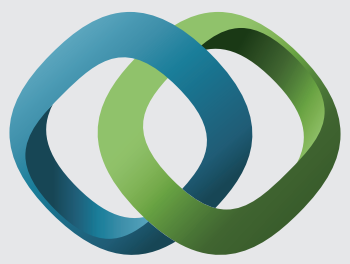

\section{Hindawi}

Submit your manuscripts at

http://www.hindawi.com
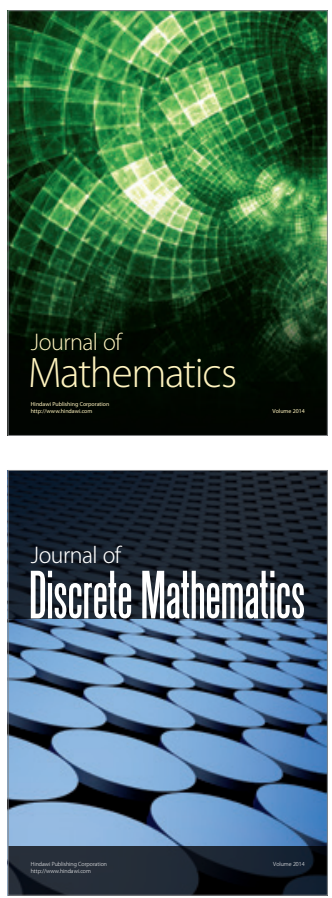

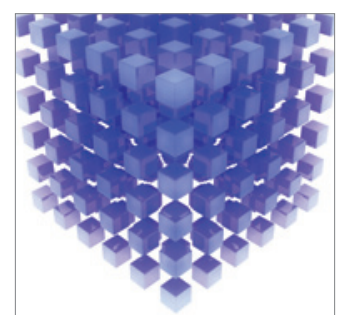

Mathematical Problems in Engineering
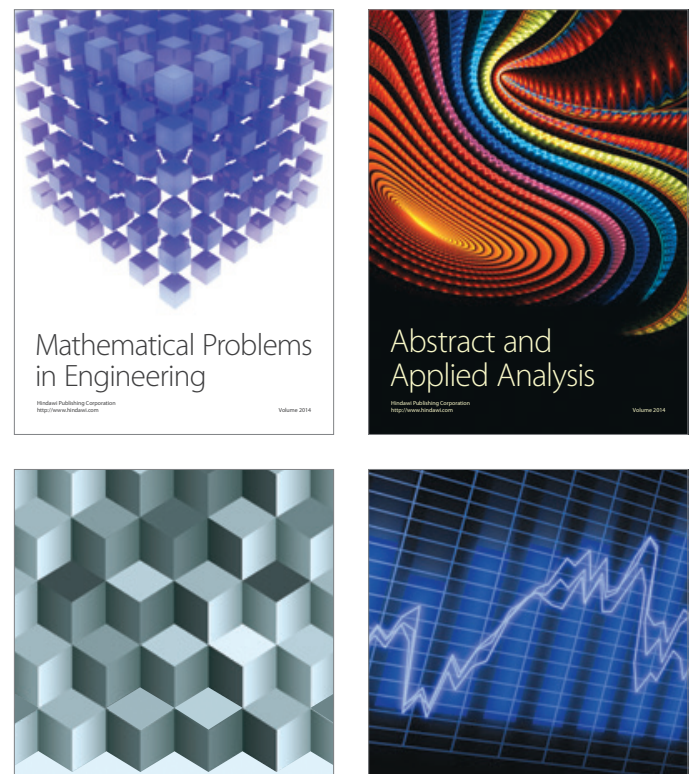

Journal of

Function Spaces

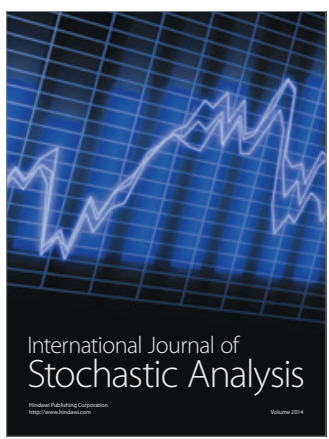

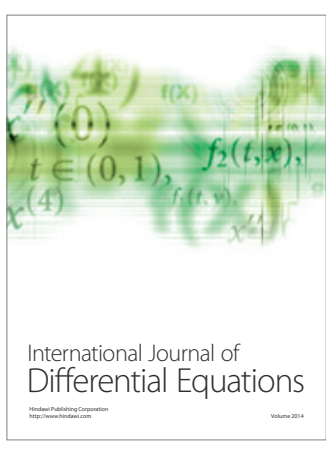
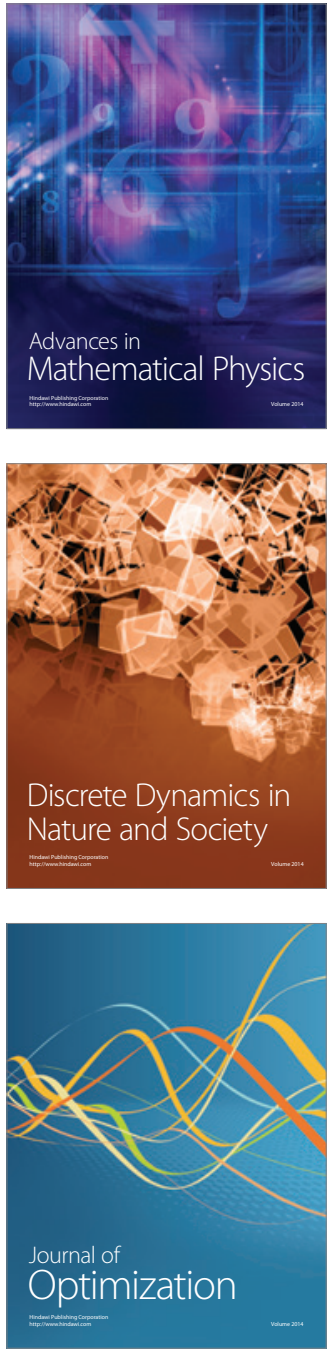